\title{
Prevention Strategies in Endometrial Carcinoma
}

\author{
Michelle L. MacKintosh ${ }^{1} \cdot$ Emma J. Crosbie ${ }^{1,2}$
}

Published online: 13 November 2018

(C) The Author(s) 2018

\begin{abstract}
Purpose of the Review To assess the most recent high-quality evidence for endometrial cancer prevention strategies. Recent Findings

- Obesity is an established risk factor for endometrial cancer.

- Weight cycling and weight gain in middle age are risk factors for endometrial cancer.

- Bariatric surgery reduces the risk of endometrial cancer by up to $81 \%$ in obese women who attain and maintain a normal weight.

- Combined oral contraceptives provide durable protection against endometrial cancer for 30 years or more.

- Ever use of the levonorgestrel intrauterine system (LNG-IUS) and inert intrauterine devices reduce endometrial cancer risk.

- The first oestrogen-based non-progestin HRT for non-hysterectomised women that contains estradiol and bazedoxifene has an effective protective effect on endometrium.
\end{abstract}

- Bisphosphonates reduce endometrial cancer risk.

Summary Weight loss and LNG-IUS would seem to be an effective strategy for preventing the development of obesity-driven endometrial cancer in the highest risk women. Future research may identify other safe and effective chemoprevention interventions, such as aspirin, bisphosphonates or metformin.

Keywords Endometrial cancer $\cdot$ Obesity $\cdot$ Risk prediction $\cdot$ Prevention strategies $\cdot$ Weight loss $\cdot$ Levonorgestrel intrauterine system (LNG-IUS)

\section{Introduction}

The incidence of endometrial cancer continues to rise unabated. Over the past 20 years, the incidence has risen by more than 50\%. In the UK alone, more than 9000 new cases are diagnosed each year and it is responsible for the deaths of more than 2000 women. The incidence in women under 50 increased by $2 \%$ every year between 1992 and 2012 [1].

This article is part of the Topical Collection on Gynecologic Cancers

Emma J. Crosbie

emma.crosbie@manchester.ac.uk

1 Department of Obstetrics and Gynaecology, St Mary's Hospital, Manchester Academic Health Science Centre, Manchester University NHS Foundation Trust, Manchester, UK

2 Gynaecological Oncology Research Group, NIHR Manchester Biomedical Research Centre, Division of Cancer Sciences, School of Medical Sciences, Faculty of Biology, Medicine and Health, University of Manchester, 5th Floor Research, St Mary's Hospital, Oxford Road, Manchester M13 9WL, UK
An ageing population, changing patterns of hysterectomy use and tamoxifen therapy may all contribute to these trends, but the overwhelming culprit is undoubtedly the obesity epidemic. Across Europe, it has been estimated that $60 \%$ of endometrial cancer cases may be due to excess weight.

Most endometrial cancers are what Bokhman termed type 1 endometrial cancers, where low-grade cancer develops in a hyperplastic endometrium, often on a background of obesity or diabetes [2]. The biological mechanisms driving type 1 endometrial carcinogenesis are incompletely understood, but adipose-derived oestrogen, unopposed by progesterone in obese postmenopausal women, is the best-supported hypothesis [3]. Obesity per se is not the whole story, however; insulin resistance, systemic inflammation and genetic predisposition all contribute to susceptibility, providing opportunities for targeted prevention strategies. Other risk factors such as tamoxifen, nulliparity, unopposed oestrogen therapy and polycystic ovary syndrome (PCOS) are well described. Many of the recognised risk factors interact with key, pro-proliferative, signal transduction pathways (Fig. 1). 
Fig. 1 An overview of signal transduction pathways dysregulated in endometrial carcinogenesis

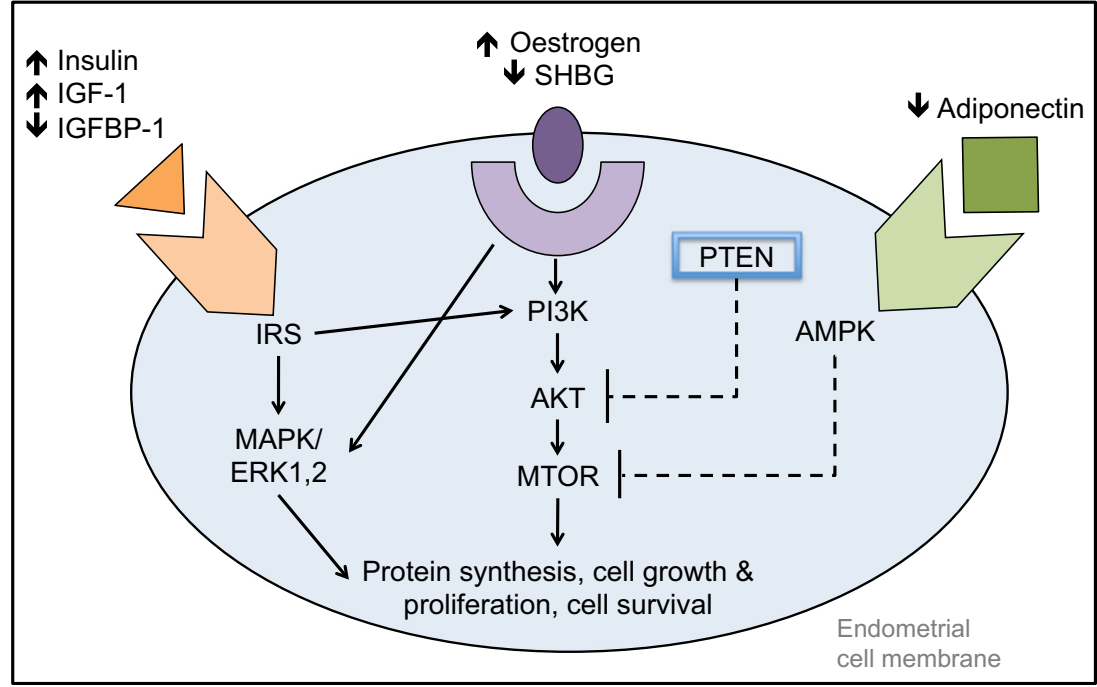

Worldwide, the prevalence of obesity (body mass index, BMI $>30 \mathrm{~kg} / \mathrm{m}^{2}$ ) has doubled in the last three decades; each year, 2.8 million people around the world die as a result of being overweight or obese. Obesity accounts for $44 \%$ of the disease burden of diabetes and $23 \%$ of that of ischaemic heart disease [4].

Despite improving survival rates, deaths from endometrial cancer have increased by almost $20 \%$ in the last decade. Whilst across all stages 5-year survival reaches $79 \%$, higher BMI is associated with increased all-cause mortality (per 10\% increase in BMI OR 1.09; 95\% CI 1.03-1.16), and disproportionate treatment-related morbidity [5].

\section{Prevention in High-Risk Groups}

\section{Lynch Syndrome}

Whilst the majority of endometrial cancer is sporadic, at least $3-5 \%$ of new diagnoses are made in women with a familial predisposition. The most common cause of this is Lynch syndrome (previously known as hereditary non-polyposis colorectal cancer, HNPCC), which is a highly penetrant autosomal dominant inherited predisposition to cancers of the endometrium, bowel, ovary and prostate, amongst others. In women with Lynch syndrome, the lifetime risk of endometrial cancer may be as high as $70 \%$, compared with a lifetime risk of $2-3 \%$ in the general population, and often precedes a colorectal cancer diagnosis by approximately 10 years [6]. Identification of families with Lynch syndrome allows quantification of cancer risk and access to cancer surveillance programmes and could prevent cancers in other family members (Table 1) [7].

Risk-reducing surgery, in the form of hysterectomy and bilateral salpingo-oophorectomy when family complete, is well established in the primary prevention of Lynch syndrome-associated endometrial and ovarian cancers (women with Lynch syndrome have a $10-12 \%$ lifetime risk of ovarian cancer) $[8,9]$. No evidence of a reduction in mortality has been demonstrated with gynaecological cancer surveillance in Lynch syndrome [10, 11]. Whilst aspirin use has demonstrated a reduction in risk for colorectal cancer, the same may not be true for endometrial cancer and more research is needed. In their primary prevention trial, Burn et al. found an unadjusted non-statistically significant reduction in endometrial cancer risk with $600 \mathrm{mg}$ aspirin once daily for up to 4 years, although it was not sufficiently powered for endometrial cancer endpoints [2].

Biomarker studies have shown that combined oral contraceptives and synthetic progestin reduce endometrial proliferation, in women with Lynch syndrome. However, it is unknown whether hormonal contraceptives are as effective for chemoprevention in Lynch syndrome as they are in the general population [12].

\section{Tamoxifen Use}

Tamoxifen is a selective oestrogen receptor modulator (SERM) used for the prevention and adjuvant treatment of breast cancer. It has been associated with increased endometrial polyps and hyperplasia, and an increased relative risk of endometrial cancer in postmenopausal women of 4.01 (95\% CI 1.7-10.9). There is no endometrial surveillance programme in place for tamoxifen users, but women and clinicians should be aware of the risks [13], and investigation of vaginal bleeding should include hysteroscopy as well as endometrial biopsy and ultrasound scan, as sensitivity and specificity of transvaginal ultrasound are low in this group. The levonorgestrel intrauterine system (LNG-IUS) has been shown to reduce the development of endometrial polyps in tamoxifen users but no convincing effect on endometrial cancer risk has yet been demonstrated [14]. 
Table 1 Summary table of the main risk factors for endometrial cancer and existing and potential prevention strategies to minimise this risk

\begin{tabular}{|c|c|c|c|c|}
\hline Risk factor & $\begin{array}{l}\text { Effect on endometrial } \\
\text { cancer risk }\end{array}$ & Proposed mechanism & $\begin{array}{l}\text { Proven methods } \\
\text { of prevention }\end{array}$ & $\begin{array}{l}\text { Potential methods } \\
\text { of prevention }\end{array}$ \\
\hline $\begin{array}{l}\text { Lynch } \\
\text { syndrome }\end{array}$ & $\begin{array}{l}\text { Lifetime risk } 70 \% \text {, cf. } 2-3 \% \\
\text { in general population }\end{array}$ & $\begin{array}{l}\text { Mutations in DNA } \\
\text { mismatch repair genes }\end{array}$ & Risk-reducing surgery & Aspirin \\
\hline Tamoxifen & $\begin{array}{l}\text { Postmenopausal RR } 4.01 \\
\quad(95 \% \text { CI } 1.7-10.9)\end{array}$ & $\begin{array}{l}\text { Oestrogenic effects } \\
\text { on endometrium }\end{array}$ & $\begin{array}{l}\text { Low threshold to } \\
\text { investigate } \\
\text { abnormal bleeding }\end{array}$ & LNG-IUS \\
\hline PCOS & $\begin{array}{l}\text { Lifetime risk } 9 \% \\
\text { OR } 2.89\end{array}$ & $\begin{array}{l}\text { Insulin resistance } \\
\text { Anovulatory cycles }\end{array}$ & $\begin{array}{l}\text { Induce regular } \\
\quad \text { withdrawal bleeds }\end{array}$ & $\begin{array}{l}\text { Weight reduction } \\
\text { Metformin hormonal contraception }\end{array}$ \\
\hline Obesity & $\begin{array}{c}\mathrm{RR} 1.59 \text { per } 5 \mathrm{~kg} / \mathrm{m}^{2} \\
\text { increase in BMI }\end{array}$ & $\begin{array}{l}\text { Activation of pro-proliferative } \\
\text { pathways (Fig. 1) } \\
\text { Anovulatory cycles }\end{array}$ & $\begin{array}{l}\text { Bariatric surgery } \\
\text { Physical activity }\end{array}$ & Non-surgical weight loss LNG-IUS \\
\hline Diabetes & RR $1.42-4.1$ & $\begin{array}{l}\text { Activation of pro-proliferative } \\
\text { pathways }\end{array}$ & Bariatric surgery & Modulation of insulin resistance \\
\hline
\end{tabular}

\section{PCOS}

PCOS affects $6-8 \%$ of women of reproductive age. Women with PCOS are overrepresented in young endometrial cancer patients, and a meta-analysis has estimated the lifetime risk of endometrial cancer in women with PCOS to be in the region of $9 \%$ (odds ratio (OR) 2.89), the increase likely driven by a toxic combination of insulin resistance and anovulatory cycles leading to oligo or amenorrhoea. For this reason, a crucial aspect of PCOS management is induction of regular withdrawal bleeds, in an attempt to reduce the risk of developing endometrial hyperplasia and cancer.

Whilst diet and weight reduction have been shown to improve the clinical manifestations of PCOS such as insulin resistance and reproductive manifestations, there is no evidence it reduces the risk of developing endometrial cancer [15]. Based on the presumption that insulin resistance is a key player in the pathogenesis of PCOS, metformin is being increasingly explored to ameliorate symptoms such as infertility and oligomenorrhoea. In vitro metformin has been shown to exert anti-tumour effects, but despite the promise of non-randomised clinical trials [16], there is no RCT evidence to support a role of metformin in endometrial cancer prevention in women with PCOS [17].

\section{Prevention in the General Population}

\section{Weight and Physical Activity}

The World Cancer Research Fund has concluded that the risk of endometrial cancer is reduced by moderate physical activity and maintaining a healthy weight [18]. Whilst obesity is a well-established risk factor for multiple types of cancer, the association is seen most strongly in endometrial cancer. Excess weight has been shown to have a non-linear, dosedependent relationship with endometrial cancer risk [19, 20].
Every $5-\mathrm{kg} / \mathrm{m}^{2}$ increase in BMI increases the relative risk (RR) by 1.59 , and at a BMI > $42 \mathrm{~kg} / \mathrm{m}^{2}$, RR $9.11(95 \% \mathrm{CI}$ 7.26-11.51). Risk is higher in women who have never used hormone replacement therapy (HRT) (RR 20.7; 95\% CI 8.2851.84) [21].

Lifestyle modification can result in 4-6\% weight reduction over 2 to 4 years, and anti-obesity drugs can lead to $7-10 \%$ weight reduction; however, only bariatric surgery produces significant and, crucially, durable results [22, 23]. Bariatric surgery has been shown to reduce cancer risk in women, particularly postmenopausal breast and endometrial cancers. A retrospective cohort study of more than 100,000 bariatric surgery patients in the USA estimated a $77-81 \%$ reduction in endometrial cancer risk associated with bariatric surgery (RR 0.29 , 95\% CI 0.26-0.32), and an even lower risk in women who attained and maintained normal weight post-bariatric surgery compared with those who remained overweight or obese (RR $0.19,95 \%$ CI $0.17-0.22$ compared with RR $0.48,95 \%$ CI $0.43-0.55$, respectively) [24].

Over 18-year median follow-up, the prospective, nonrandomised SOS Study has demonstrated that bariatric surgery significantly reduces the risk of endometrial cancer (hazard ratio (HR) $0.56,95 \%$ CI $0.35-0.89, p=0.014$ ) in over 2800 women who underwent surgical or conventional weight management treatment. Other cancers were also reduced after bariatric surgery and the number needed to treat (NNT) to prevent one cancer over 10 years with bariatric surgery was $31\left[25^{\bullet}\right]$.

Studies continue to show that as well as excess body weight being a risk factor for endometrial cancer, so too is adult weight gain, weight cycling, the duration of overweight/obesity and possibly being overweight in childhood/at age 18 [26, 27•, 28-30]. In the NOWAC study, a $5-\mathrm{kg}$ weight gain was significantly associated with increased risk of postmenopausal endometrial cancer, with a dose-response relationship with increasing weight gain, emphasising the importance of maintaining a stable weight 
in "middle adulthood" [28]. Weight gain and weight cycling have also been shown to be significantly associated with the development of postmenopausal endometrial cancer in the Women's Health Initiative Observational Study, of 80,943 women including 788 cases of endometrial cancer over 20 years of follow-up [27•]. Weight cycling four to six times increased risk of endometrial cancer by $38 \%$ compared with weight-stable women.

There is now convincing evidence that women with higher physical activity levels have a lower risk of endometrial cancer than women with the lowest activity levels, in particular overweight or obese women with high activity levels (BMI <25 RR 0.97; 95\% CI 0.84-1.13 cf. BMI $\geq 25$ RR $0.69 ; 95 \%$ CI $0.52-0.91)$ [31, 32•]. Studies of physical activity are limited by the activity being selfreported and more difficult to ascribe a quantitative value to, and heavily intertwined with, other confounding risk factors such as adiposity.

Arthur et al. modelled a Healthy Lifestyle Index (HLI) in 3185 women and reported that for every unit increase in HLI, there was a $5 \%$ reduction in endometrial cancer risk. When they directly compared the low vs. high HLI groups, there was a $46 \%$ reduction in risk [33 ${ }^{\circ}$.

\section{Diabetes and Insulin Resistance}

Diabetes may increase the risk of endometrial cancer; however, meta-analyses are frequently plagued by the confounders of inactivity and obesity, as alternative or additional endometrial cancer risk factors. After multivariate adjustment, studies have estimated the increase in relative risk to be in the region of 1.42 to 4.1 [34].

An umbrella review in 2015 supported an association between type 2 diabetes and endometrial cancer. It examined 8174 cases, found no significant bias within the studies, and reported Summary Random Effects estimates of 1.97 (95\% CI 1.71-2.27), and 95\% prediction intervals of 1.23 to 3.16 [35]. Sacerdote et al. published the results of their meta-analysis which supported an association between endometrial cancer and diabetes (RR 1.65, 95\% CI 1.5-1.81), although high heterogeneity between studies was found [36].

It has not been proven that modulation of insulin resistance is an effective mechanism for preventing EC [19, 37]. Many studies assess surrogate markers rather than clinical end points, and a definitive chemoprevention study is unlikely as it would require huge numbers and many years of follow-up. Randomised biomarker studies have so far failed to demonstrate a reduction in endometrial proliferation with $2-16$ weeks of metformin treatment $[38,39]$. Similarly, metformin has not been shown to reduce endometrial cancer risk (OR $1.05,95 \%$ CI $0.82-1.35, p=0.7)$, but may improve risk of recurrence or overall survival [40].

\section{Hormonal Treatment}

Long-term follow-up data provides convincing evidence that use of combined oral contraceptives (COC) is associated with a significant and enduring reduction in the lifetime risk of endometrial cancer. Iversen et al. demonstrate that the protective effects of COC persist for at least 30 years, in this updated follow-up study of users who were recruited between 1968 and 1969 [41•]. The faculty of Sexual and Reproductive Health advises that at a BMI $>35 \mathrm{~kg} / \mathrm{m}^{2}$, the risks of COC are likely to outweigh the benefits (UKMEC 3 recommendation), which precludes its use as chemoprevention in the most obese women [42].

Oral, injectable and intrauterine progestin use has been shown to reduce the risk of endometrial cancer. Data from the Finnish Cancer Registry showed a standardised incidence ratio of 0.46 for endometrial cancer in users of the LNG-IUS. The NOWAC study was a Norwegian population-based prospective cohort study. Median follow-up was 12.5 years; $9 \%$ of the cohort reported LNGIUS use during or prior to 1998-2007. After adjusting for BMI, activity, age at start of follow-up, combined oral contraceptive use, menopausal status and parity ever-users of LNG-IUS had RR of endometrial cancer of 0.34 (95\% CI 0.18-0.65) compared with never-users [43•].

Almost 25 years ago, the harmful effects of unopposed oestrogen HRT in women with a uterus were apparent. Sequential HRT has also been shown to increase the risk of endometrial cancer, with risk being inversely proportional to the number of days progestin is given for. Continuous combination has not been shown to increase endometrial cancer risk and may even reduce it, presumably because of the protective effects of progesterone on the endometrium [44].

Recent years have seen the emergence of the first oestrogen-based, progestin-free oral menopausal HRT for non-hysterectomised women. Conjugated oestrogens with the SERM bazedoxifene (CE/BZA) minimise estrogenic effects on endometrium and breast whilst effectively addressing menopausal symptoms and protecting against osteoporosis. A similar randomised, double-blind study of $17 \beta$-estradiol/raloxifene did not provide adequate endometrial protection. CE/ BZA has been studied in five RCTs involving more than 7500 women and no increase in endometrial hyperplasia was found. It may be an option for women who poorly tolerate the side effects of progestins [45•].

\section{Bisphosphonates}

Preclinical and animal model studies have shown that bisphosphonates have anti-tumour effects, in part through induction of apoptosis and inhibition of proliferation and angiogenesis. They have been shown to affect the growth 
and metastasis of gynaecological cancers in cell lines and animal models. A meta-analysis of cohort and case control studies demonstrated a statistically significant endometrial cancer risk reduction with 1-3 years of bisphosphonate use in 6499 endometrial cancer cases from 226,560 participants. With 3 or more years of bisphosphonate use, a $56 \%$ reduction in endometrial cancer risk was seen (pooled RR $0.44 ; 95 \%$ CI $0.28-0.7)[46 \bullet]$.

\section{Aspirin}

In their 2005 randomised controlled primary prevention trial of 39,876 women in the Women's Health Study, Cook et al. found no association between low-dose aspirin use (100 mg/alternate days cf. placebo) and endometrial cancer risk (RR 1.22, 95\% CI 0.94-1.58, $p=0.14$ ) [47]. A 2016 meta-analysis of cohort and case control studies did suggest a small-to-modest protective effect with aspirin use, and a weak effect with regular NSAID use, from statistically nonsignificant pooled risk estimates [48]. The results should be interpreted with caution; only cohort and case control studies were included, and doses and duration of aspirin use varied widely between the studies included. A 2018 metaanalysis by Qiao and Yang et al. also found an inverse association between aspirin use and endometrial cancer risk (RR 0.92, 95\% CI 0.85-0.99) from 8410 endometrial cancer cases in six case control studies, and 3127 endometrial cancer cases in eight cohort studies. Again, it is unclear what dose of aspirin participants were taking [49].

\section{Reproductive}

Continued efforts to promote breastfeeding may help to reduce endometrial cancer risk in the general population. In their meta-analysis, Jordan et al. demonstrated an $11 \%$ reduction in endometrial cancer risk in women who had breastfed (pooled OR 0.89; 95\% CI 0.81-0.98) comparing 8981 endometrial cancer cases with 17,241 controls from cohort and case control studies [50].

Felix et al. presented a pooled analysis of individual level data from 18 epidemiological studies, which was the largest investigation of IUD use and EC risk to date (8801 cases and 15,357 controls). Pooled OR for ever-use of IUD was 0.81 (95\% CI 0.74 to 0.9 ) compared with never-use with the inverse association being strongest in users of inert IUDs, and weaker in users of copper, hormonal or a combination of types of IUDs. Nulliparous IUD users gained more benefit than parous IUD users. Proposed mechanisms of action by which IUDs reduce endometrial cancer risk are increased decidual loss, alterations in hormone receptor expression and stimulation of an inflammatory microenvironment in the uterus [51].

\section{Dietary}

\section{Soy}

A meta-analysis of 13 studies (no RCTs) demonstrated a weak inverse relationship between high isoflavone (soy) consumption and endometrial cancer risk [52]. Novasoy and genistein have been shown to inhibit proliferation by reducing oestrogen receptor (ER) alpha expression and interacting with the pro-proliferative AKT/MTOR/MAPK pathway and have been suggested as potential therapeutic agents [53].

\section{Coffee}

The largest meta-analysis in the literature, including 1.4 million participants and 10,100 cases of endometrial cancer, with follow-up of 11 to 20 years concluded there was a dose-dependent reduction in endometrial cancer risk with coffee intake, stronger but not limited to caffeinated coffee. One cup of caffeinated coffee per day was associated with a 7\% reduction in endometrial cancer risk (RR $0.93,95 \%$ CI $0.89-0.97$ ), compared with a $4 \%$ risk reduction with one cup of decaffeinated coffee/day (RR 0.96, 95\% CI 0.92-0.99) [54•].

Merritt et al. conducted a nutrient-wide association study (NWAS) on data from 1303 endometrial cancer cases from the EPIC study and 1531 endometrial cancer cases from the Nurses Health Studies and confirmed an inverse association between coffee intake and endometrial cancer risk [55].

Several factors are thought to contribute to the protective effect of coffee. Caffeine is associated with levels of sex hormone-binding globulin (SHBG) and, as a consequence, levels of bioavailable oestrogen and testosterone. Coffee contains antioxidants and chlorogenic acid, which may inhibit glucose absorption. Coffee has been shown to have an inverse relationship with plasma $\mathrm{C}$ peptide levels and the risk of diabetes mellitus [56].

\section{Tea}

A meta-analysis by Zhou et al., which included six case control or cohort studies, not all of which were controlled for physical activity, found a reduced risk of endometrial cancer with higher intake of green tea. One cup per day was associated with an $11 \%$ risk reduction in a dose-response analysis (RR 0.89; 95\% CI 0.84-0.94). No protective effect was seen with black tea. Green tea has higher levels of catechins than black tea, such as epigallocatechin gallate, which has been found to induce apoptosis and cell cycle arrest, and inhibit oestrogen-induced activation of endometrial cells. 


\section{Our Approach}

The main focus of our research is the prevention and early detection of endometrial cancer. These themes ranked as the most important endometrial cancer research priorities for patients, carers and healthcare professionals in our awardwinning James Lind Alliance Priority Setting Partnership [57]. We found a high prevalence of occult endometrial abnormality in obese women undergoing bariatric surgery, and witnessed their reversal to healthy endometrium after bariatric surgery-induced weight loss in some cases [58]. Based on these findings, we have made local arrangements to facilitate the provision of bariatric surgery to obese women diagnosed with an obesity-related precancerous endometrial lesion and have ongoing work exploring non-surgical treatments for lowgrade early-stage endometrial cancers in selected patients.

Our aim is to identify a high-risk endometrial tissue signature that predicts those women at greatest risk of developing endometrial cancer to target for prevention measures (such as weight loss, LNG-IUS \pm chemoprevention agents). Our theoretical risk prediction model will facilitate the identification of women for stratified prevention interventions and ongoing work seeks to validate our model in large UK populations [59]. Such interventions may also be useful in the posttreatment setting, to reduce the risk of cancer recurrence, although there is currently no evidence to support this [60]. Achieving and maintaining weight loss is likely to have health benefits beyond the endometrium in obese postmenopausal women, for example by reducing the risk of type 2 diabetes mellitus [61] and cardiovascular events [62].

\section{Future Research}

Future research must target the gaps in our knowledge. Can we identify those at highest risk of developing endometrial cancer and how best can we prevent it? Well-designed observational and interventional studies may address the questions of aspirin, NSAID and other potential chemoprevention agents. The degree of benefit will need to be weighed against the potential adverse effects of such drugs.

\section{Conclusions}

For now, it would seem that prevention strategies should focus on minimising risk through weight reduction and/or stability, improving access to bariatric surgery, and by educating women and healthcare professionals about the importance of weight and activity levels on their risk of type 1 endometrial cancer. The LNG-IUS is an effective tool for women at highest risk.

Future research may provide us with the justification to use aspirin, metformin or bisphosphonates for chemoprevention but at present the evidence for either their efficacy or their long-term safety in high-risk women is lacking.

Use of the Healthy Lifestyle Index may help women take control of minimising their personal risk and help healthcare professionals quantify risks for patients. Work must continue in identifying a high-risk molecular/phenotypic signature for targeted prevention, and efforts to identify women with Lynch syndrome must continue.

\section{Compliance with Ethical Standards}

Conflict of Interest Michelle L. MacKintosh declares that she has no conflict of interest. Emma J. Crosbie is supported by a grant from the NIHR Manchester Biomedical Research Centre.

Human and Animal Rights and Informed Consent This article does not contain any studies with human or animal subjects performed by any of the authors.

Open Access This article is distributed under the terms of the Creative Commons Attribution 4.0 International License (http:// creativecommons.org/licenses/by/4.0/), which permits unrestricted use, distribution, and reproduction in any medium, provided you give appropriate credit to the original author(s) and the source, provide a link to the Creative Commons license, and indicate if changes were made.

\section{References}

Papers of particular interest, published recently, have been highlighted as:

- Of importance

1. Beavis AL, Smith AJB, Fader AN. Lifestyle changes and the risk of developing endometrial and ovarian cancers: opportunities for prevention and management. Int J Womens Health. 2016;8:151-67.

2. Burn J, Gerdes A-M, Macrae F, Mecklin J-P, Moeslein G, Olschwang $\mathrm{S}$, et al. Long-term effect of aspirin on cancer risk in carriers of hereditary colorectal cancer: an analysis from the CAPP2 randomised controlled trial. Lancet Lond Engl. 2011;378(9809): 2081-7.

3. MacKintosh M, Crosbie E. Obesity-driven endometrial cancer: is weight loss the answer? BJOG Int J Obstet Gynaecol. 2013 Jun;120(7):791-4.

4. Statistics on obesity, physical activity and diet: England, 2012. [cited 2012 Nov 7]. Available from: http://www.ic.nhs.uk/statisticsand-data-collections/health-and-lifestyles/obesity/statistics-onobesity-physical-activity-and-diet-england-2012.

5. Uccella S, Bonzini M, Palomba S, Fanfani F, Ceccaroni M, Seracchioli R, et al. Impact of obesity on surgical treatment for endometrial cancer: a multicenter study comparing laparoscopy vs open surgery, with propensity-matched analysis. J Minim Invasive Gynecol. 2016 Jan;23(1):53-61.

6. Ryan NAJ, Morris J, Green K, Lalloo F, Woodward ER, Hill J, et al. Association of mismatch repair mutation with age at cancer onset in Lynch syndrome: implications for stratified surveillance strategies. JAMA Oncol. 2017;3(12):1702-6.

7. Randall LM, Pothuri B. The genetic prediction of risk for gynecologic cancers. Gynecol Oncol. 2016;141(1):10-6. 
8. Schmeler KM, Lynch HT, Chen L, Munsell MF, Soliman PT, Clark $\mathrm{MB}$, et al. Prophylactic surgery to reduce the risk of gynecologic cancers in the Lynch syndrome. N Engl J Med. 2006;354(3):261-9.

9. Sundar S, Balega J, Crosbie E, Drake A, Edmondson R, Fotopoulou $\mathrm{C}$, et al. BGCS uterine cancer guidelines: recommendations for practice. Eur J Obstet Gynecol Reprod Biol. 2017;213:71-97.

10. Auranen A, Joutsiniemi T. A systematic review of gynecological cancer surveillance in women belonging to hereditary nonpolyposis colorectal cancer (Lynch syndrome) families. Acta Obstet Gynecol Scand. 2011;90(5):437-44.

11. Ryan NAJ, Evans DG, Green K, Crosbie EJ. Pathological features and clinical behavior of Lynch syndrome-associated ovarian cancer. Gynecol Oncol. 2017;144(3):491-5.

12. Lu KH, Loose DS, Yates MS, Nogueras-Gonzalez GM, Munsell MF, Chen L-M, et al. Prospective multicenter randomized intermediate biomarker study of oral contraceptive versus depo-provera for prevention of endometrial cancer in women with Lynch syndrome. Cancer Prev Res (Phila). 2013;6(8):774-81.

13. Funston G, O'Flynn H, Ryan NAJ, Hamilton W, Crosbie EJ. Recognizing gynecological cancer in primary care: risk factors, red flags, and referrals. Adv Ther. 2018;35(4):577-89.

14. Wong AWY, Chan SSC, Yeo W, Yu M-Y, Tam W-H. Prophylactic use of levonorgestrel-releasing intrauterine system in women with breast cancer treated with tamoxifen: a randomized controlled trial. Obstet Gynecol. 2013;121(5):943-50.

15. Faghfoori Z, Fazelian S, Shadnoush M, Goodarzi R. Nutritional management in women with polycystic ovary syndrome: a review study. Diabetes Metab Syndr. 2017;11(Suppl 1):S429-32.

16. Mitsuhashi A, Sato Y, Kiyokawa T, Koshizaka M, Hanaoka H, Shozu M. Phase II study of medroxyprogesterone acetate plus metformin as a fertility-sparing treatment for atypical endometrial hyperplasia and endometrial cancer. Ann Oncol Off J Eur Soc Med Oncol. 2016;27(2):262-6.

17. Shafiee MN, Khan G, Ariffin R, Abu J, Chapman C, Deen S, et al. Preventing endometrial cancer risk in polycystic ovarian syndrome (PCOS) women: could metformin help? Gynecol Oncol. 2014;132(1):248-53.

18. WCRF/AICR. Food, nutrition, physical activity, and the prevention of cancer: a global perspective. Washington DC: AICR; 2007.

19. Sivalingam VN, Myers J, Nicholas S, Balen AH, Crosbie EJ. Metformin in reproductive health, pregnancy and gynaecological cancer: established and emerging indications. Hum Reprod Update. 2014;20(6):853-68.

20. Renehan AG, MacKintosh ML, Crosbie EJ. Obesity and endometrial cancer: unanswered epidemiological questions. BJOG Int $\mathrm{J}$ Obstet Gynaecol. 2016;123(2):175-8.

21. Crosbie E, Zwahlen M, Kitchener H, Egger M, Renehan A. Body mass index, hormone replacement therapy and endometrial cancer risk: a meta analysis. Cancer Epidemiol Biomark Prev. 2010;19(12):3119-30.

22. Davidson MH, Hauptman J, DiGirolamo M, et al. Weight control and risk factor reduction in obese subjects treated for 2 years with orlistat: a randomized controlled trial. JAMA. 1999;281(3):235-42.

23. Ryan DH, Johnson WD, Myers VH, Prather TL, McGlone MM, Rood J, et al. Nonsurgical weight loss for extreme obesity in primary care settings: results of the Louisiana Obese Subjects Study. Arch Intern Med. 2010;170(2):146-54

24. Ward KK, Roncancio AM, Shah NR, Davis M-A, Saenz CC, McHale MT, et al. Bariatric surgery decreases the risk of uterine malignancy. Gynecol Oncol. 2014;133(1):63-6.

25. Anveden A, Taube M, Peltonen M, Jacobson P, AnderssonAssarsson JC, Sjoholm K, et al. Long-term incidence of femalespecific cancer after bariatric surgery or usual care in the Swedish Obese Subjects Study. Gynecol Oncol. 2017;145(2):224-9 Prospective non-randomised study with 18-year follow-up demonstrating a significant reduction in risk of endometrial cancer after bariatric surgery HR 0.56; 95\% CI 0.35-0.89, $p=0.014$.

26. Stevens VL, Jacobs EJ, Patel AV, Sun J, Gapstur SM, McCullough ML. Body weight in early adulthood, adult weight gain, and risk of endometrial cancer in women not using postmenopausal hormones. Cancer Causes Control. 2014;25(3):321-8.

27. Welti LM, Beavers DP, Caan BJ, Sangi-Haghpeykar H, Vitolins MZ, Beavers KM. Weight fluctuation and cancer risk in postmenopausal women: the women's health initiative. Cancer Epidemiol Biomarkers Prev. 2017;26(5):779-86 Data from the WHI Observational Study of 80,943 women (788 cases of endometrial cancer) demonstrated that both weight gain and weight cycling increase endometrial cancer risk (weight cycling HR 1.23, 95\% CI 1.01-1.49).

28. da Silva M, Weiderpass E, Licaj I, Lissner L, Rylander C. Excess body weight, weight gain and obesity-related cancer risk in women in Norway: the Norwegian Women and Cancer study. Br J Cancer. 2018;11:646-56.

29. Arnold M, Jiang L, Stefanick ML, Johnson KC, Lane DS, LeBlanc ES, et al. Duration of adulthood overweight, obesity, and cancer risk in the Women's Health Initiative: a longitudinal study from the United States. PLoS Med. 2016;13(8):e1002081.

30. Aarestrup J, Gamborg M, Ulrich LG, Sorensen TIA, Baker JL. Childhood body mass index and height and risk of histologic subtypes of endometrial cancer. Int J Obes. 2005;40(7):1096-102.

31. Schmid D, Behrens G, Keimling M, Jochem C, Ricci C, Leitzmann M. A systematic review and meta-analysis of physical activity and endometrial cancer risk. Eur J Epidemiol. 2015;30(5):397-412.

32. Moore SC, Lee I-M, Weiderpass E, Campbell PT, Sampson JN, Kitahara CM, et al. Association of leisure-time physical activity with risk of 26 types of cancer in 1.44 million adults. JAMA Intern Med. 2016;176(6):816-25 Pooled data from 12 European and US cohorts (1.44 million participants, 5346 cases of endometrial cancer) found a significant inverse association between cancer risk and activity levels in women who were overweight or obese, when adjusted for BMI.

33. Arthur R, Kirsh VA, Kreiger N, Rohan T. A healthy lifestyle index and its association with risk of breast, endometrial, and ovarian cancer among Canadian women. Cancer Causes Control. 2018;29(6):485-93 This study used a Healthy Lifestyle Index to assess the association of modifiable risk factors with endometrial cancer risk, in 177 cases of endometrial cancer from the Canadian Study of Diet, Lifestyle and Health. Each unit increase in Healthy Lifestyle Index was associated with a $5 \%$ reduction in endometrial cancer risk (HR 0.95; 95\% CI 0.90-0.99).

34. Friberg E, Orsini N, Montzoros C, Wolk A. Diabetes mellitus and risk of endometrial cancer: a meta-analysis. Diabetologia. 2007;50(7):1365-74.

35. Tsilidis KK, Kasimis JC, Lopez DS, Ntzani EE, Ioannidis JPA. Type 2 diabetes and cancer: umbrella review of meta-analyses of observational studies. BMJ. 2015;350:g7607.

36. Sacerdote C, Ricceri F. Epidemiological dimensions of the association between type 2 diabetes and cancer: a review of observational studies. Diabetes Res Clin Pract. 2018;143:369-77.

37. Kitson S, Crosbie E. Hormonal and metabolic strategies to overcome insulin resistance and prevent endometrial Cancer. In: Berger NA et al, editors. Focus on Gynecologic Malignancies, Energy Balance and Cancer.

38. Sivalingam VN, Kitson S, McVey R, Roberts C, Pemberton P, Gilmour K, et al. Measuring the biological effect of presurgical metformin treatment in endometrial cancer. Br J Cancer. 2016 Feb 2;114(3):281-9.

39. Yates MS, Coletta AM, Zhang Q, Schmandt RE, Medepalli M, Nebgen D, et al. Prospective randomized biomarker study of 
metformin and lifestyle intervention for prevention in obese women at increased risk for endometrial cancer. Cancer Prev Res (Phila). 2018;11(8):477-90.

40. Chu D, Wu J, Wang K, Zhao M, Wang C, Li L, et al. Effect of metformin use on the risk and prognosis of endometrial cancer: a systematic review and meta-analysis. BMC Cancer. 2018;18(1):438.

41. Iversen L, Sivasubramaniam S, Lee AJ, Fielding S, Hannaford PC. Lifetime cancer risk and combined oral contraceptives: the Royal College of General Practitioners' Oral Contraception Study. Am J Obstet Gynecol. 2017;216(6):580.e1-9 Long-term follow-up data from a prospective observational study showing that ever-use of $\mathrm{COC}$ has a protective effect against cancers, including endometrial (incidence rate $0.66,99 \%$ CI $0.48-0.89$ ) that persists for at least 30 years.

42. Faculty of Sexual \& Reproductive Healthcare. The UK Medical Eligibility Criteria for Contraceptive Use. Royal College of Obstetricians \& Gynaecologists; 2009.

43. Jareid M, Thalabard J-C, Aarflot M, Bovelstad HM, Lund E, Braaten T. Levonorgestrel-releasing intrauterine system use is associated with a decreased risk of ovarian and endometrial cancer, without increased risk of breast cancer. Results from the NOWAC Study. Gynecol Oncol. 2018;149(1):127-32 Population-based prospective cohort study of women in the Norwegian Women and Cancer Study, showing ever-use of LNG-IUS reduced the risk of endometrial cancer (RR $0.22,95 \%$ CI $0.13-0.40$ ) compared with never-use.

44. Sjogren LL, Morch LS, Lokkegaard E. Hormone replacement therapy and the risk of endometrial cancer: a systematic review. Maturitas. 2016;91:25-35.

45. Parish SJ, Gillespie JA. The evolving role of oral hormonal therapies and review of conjugated estrogens/bazedoxifene for the management of menopausal symptoms. Postgrad Med. 2017;129(3): 340-51 First review article detailing the potential of conjugated oestrogen/bazedoxifene for menopausal HRT for nonhysterectomised women, which may be useful in women who cannot take progestagens.

46. Ou Y-J, Chiu H-F, Wong Y-H, Yang Y-H. Bisphosphonate use and the risk of endometrial cancer: a meta-analysis of observational studies. Pharmacoepidemiol Drug Saf. 2016;25(10):1107-15 Meta-analysis of cohort and case control studies demonstrating a statistically significant reduction in endometrial cancer risk with bisphosphonate use, which increases with greater duration of treatment ( 3 years pooled RR $0.44 ; 95 \%$ CI $0.28-0.70$ ).

47. Cook NR, Lee I-M, Gaziano JM, Gordon D, Ridker PM, Manson JE, et al. Low-dose aspirin in the primary prevention of cancer: the Women's Health Study: a randomized controlled trial. JAMA. 2005;294(1):47-55.

48. Verdoodt F, Friis S, Dehlendorff C, Albieri V, Kjaer SK. Nonsteroidal anti-inflammatory drug use and risk of endometrial cancer: a systematic review and meta-analysis of observational studies. Gynecol Oncol. 2016;140(2):352-8.

49. Qiao Y, Yang T, Gan Y, Li W, Wang C, Gong Y, et al. Associations between aspirin use and the risk of cancers: a meta-analysis of observational studies. BMC Cancer. 2018;18(1):288.

50. Jordan VC. The 4Ps of breast cancer chemoprevention: putting proven principles into practice. Cancer Prev Res (Phila). 2017;10(4):219-22.
51. Felix AS, Gaudet MM, La Vecchia C, Nagle CM, Shu XO, Weiderpass $\mathrm{E}$, et al. Intrauterine devices and endometrial cancer risk: a pooled analysis of the Epidemiology of Endometrial Cancer Consortium. Int J Cancer. 2015;136(5):E410-22.

52. Zhong X-S, Ge J, Chen S-W, Xiong Y-Q, Ma S-J, Chen Q. Association between dietary isoflavones in soy and legumes and endometrial cancer: a systematic review and meta-analysis. J Acad Nutr Diet. 2018;118(4):637-51.

53. Malloy KM, Wang J, Clark LH, Fang Z, Sun W, Yin Y, et al. Novasoy and genistein inhibit endometrial cancer cell proliferation through disruption of the AKT/mTOR and MAPK signaling pathways. Am J Transl Res. 2018;10(3):784-95.

54. Zhou Q, Luo M-L, Li H, Li M, Zhou J-G. Coffee consumption and risk of endometrial cancer: a dose-response meta-analysis of prospective cohort studies. Sci Rep. 2015;5:13410 A metaanalysis of over 1.5 million participants and 10,100 endometrial cancer cases confirmed a dose-dependent endometrial cancer risk with coffee intake, which was greater but not limited to caffeinated coffee.

55. Merritt MA, Tzoulaki I, Tworoger SS, De Vivo I, Hankinson SE, Fernandes J, et al. Investigation of dietary factors and endometrial cancer risk using a nutrient-wide association study approach in the EPIC and Nurses' Health Study (NHS) and NHSII. Cancer Epidemiol Biomarkers Prev. 2015;24(2):466-71.

56. Bravi F, Scotti L, Bosetti C, Gallus S, Negri E, La Vecchia C, et al. Coffee drinking and endometrial cancer risk: a metaanalysis of observational studies. Am J Obstet Gynecol. 2009;200(2):130-5.

57. Wan YL, Beverley-Stevenson R, Carlisle D, Clarke S, Edmondson RJ, Glover S, et al. Working together to shape the endometrial cancer research agenda: the top ten unanswered research questions. Gynecol Oncol. 2016;143(2):287-93.

58. MacKintosh M, Derbyshire A, McVey R, Bolton J, Nickkho-Amiry M, Higgins $C$, et al. The impact of obesity and bariatric surgery on circulating and tissue biomarkers of endometrial cancer risk. Int $\mathrm{J}$ Cancer. 2018; In press.

59. Kitson SJ, Evans DG, Crosbie EJ. Identifying high-risk women for endometrial cancer prevention strategies: proposal of an endometrial cancer risk prediction model. Cancer Prev Res (Phila). 2017;10(1):1-13.

60. Kitson S, Ryan N, MacKintosh ML, Edmondson R, Duffy JM, Crosbie EJ. Interventions for weight reduction in obesity to improve survival in women with endometrial cancer. Cochrane Database Syst Rev. 2018 [cited 2018 Oct 1]; Available from: https://www.readcube.com/articles/10.1002/14651858.CD012513. pub2.

61. Kitson SJ, Lindsay J, Sivalingam VN, Rutter MK, Crosbie EJ. High prevalence of metabolic syndrome in women newly diagnosed with endometrial cancer. Gynecol Oncol Rep. 2018 Aug 23 [cited 2018 Oct 1]; Available from: http://www.sciencedirect.com/science/ article/pii/S2352578918300808.

62. Kitson SJ, Lindsay J, Sivalingam VN, Lunt M, Ryan NAJ, Edmondson RJ, et al. The unrecognized burden of cardiovascular risk factors in women newly diagnosed with endometrial cancer: a prospective case control study. Gynecol Oncol. 2018;148(1):154-60. 